\title{
Metallic Soaps of Ricinoleic Acid: Adsorption Isotherms and Effects of Ionic Charge
}

\author{
Itodo A. $\mathbf{U}^{1}$, Etim E. $\mathbf{E}^{2 *}$, Mbakara, I. $\mathbf{E}^{3}$ \\ ${ }^{I}$ Department of Chemistry and Agro-Chemical Technology, University of Agriculture Makurdi, Nigeria \\ ${ }^{2}$ Department of Chemical Sciences, Federal University, Wukari, Nigeria \\ ${ }^{3}$ Department of Chemistry, University of Ibadan
}

*Corresponding Author: Etim E. E, Department of Chemical Sciences, Federal University, Wukari, Nigeria

\begin{abstract}
Hematite is the major and common metallic ore in Kogi state of Nigeria. It is readily available in large quantities and at considerably low price. In the physical standpoint, it looks porously oriented for one to crave its use as adsorbent. The purpose of this paper is to present the results of performance analysis of adsorption of derived metallic soaps of castor (ricinus) seed oil onto hematite. Different chemical ionic surfaces were created by spiking or impregnating metallic soap adsorbates with salts of $K, B a, A l$, Nitrate, sulphates and phosphates respectively. This is to generate $+1,+2,+3,-1,-2$ and -3 ionic charged surfaces. Adsorption capacity (qe) values increased linearly to an equilibration point for cationic $\left(\mathrm{K}^{+}, \mathrm{Ba}^{2+}\right.$ and $\left.\mathrm{Al}^{3+}\right)$ spiked ricinus soaps adsorption.

The reverse was the case observed for the anionic $\left(\mathrm{NO}_{3}{ }^{-} \mathrm{SO}_{4}{ }^{2-}\right.$ and $\left.\mathrm{PO}_{4}{ }^{3-}\right)$ spiked soaps of Ricinus oil where qe at equilibration decreases with increase in ionic charge. This work further arrayed the respective isotherm constants ( $A, b, n, R_{L}, K a, B D, q e, q s, q m$ etc) from Langmuir isotherm, Freundlich isotherm, Temkin, BET and Dubinin Radushkevich isotherm models. Generally, this research unveiled that the role played by the effect of ionic charges and ionic concentration cannot be overemphasized.
\end{abstract}

Keywords: adsorption, isotherms, ionic charge, metallic soaps, ricinus oil, castor seed

\section{INTRODUCTION}

Adsorption isotherms are basic requirement for the design of adsorption system [1] it is basically imported to describe how solute interacts with biosorbent, and it is critical for optimizing the use of adsorbent. Equilibrium relationships between sorbents and sorbates are described by sorption isotherms which give the capacity of a sorbent for a sorbate [2]. Isotherms can be deduced by designing batch reactors at fixed temperatures. Linear regression is frequently used to determine the fitting isotherm. In this present work, statistical linear least squares method via the correlation coefficient (R2) was used [2].Specific surface area is defined as the accessible area of solid surface per unit mass of material. Because the surrounding phase can modify the surface area, each method that was studied for measuring surface had shortcomings [3].

An isotherm is a functional expression for the variation of adsorption relative to the concentration of adsorbate in the bulk solution at constant temperature [4]. It describes the relation of between the adsorbate retained by the activated carbon and the adsorbate equilibrium concentration [4]. It was defined as a graphical representation showing the relationship betweenthe amounts of the adsorbate in $\mathrm{mg}$, adsorbed by a unit weight of adsorbent in $\mathrm{g}$ for example activated carbon and the amount of adsorbate remaining in a test medium of equilibrium. of equilibrium. It represents the distribution of adsorbable solute between the liquid and solid phases at various equilibrium concentrations [5]. Sorption isotherm is dependent on data that are specific for each system and the isotherm must be determined for every application. An adsorption isotherm besides providing information on the course taken by the system under study in a concise form, it also indicates how efficiently an adsorbent is in terms of the economic feasibility of the carbons in commercial applications and for the specific solute [5]. 


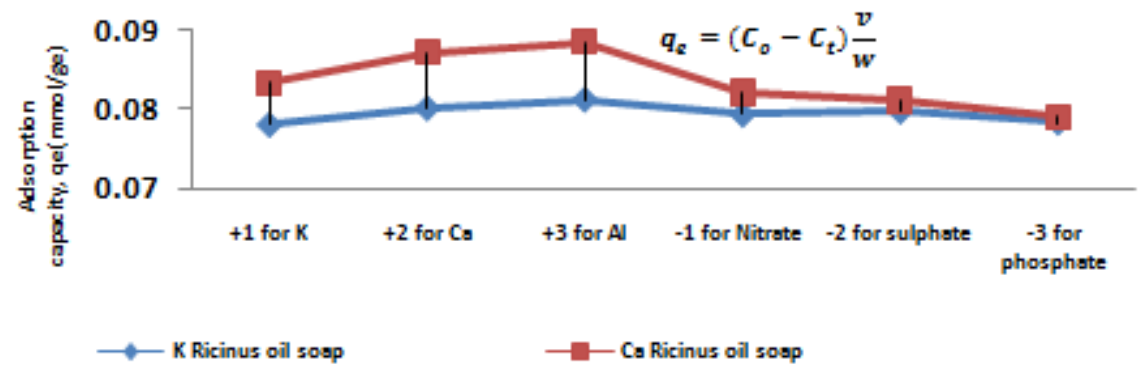

Researchers have studied the adsorption of surfactants onto some mineral surfaces in aqueous medium as prelude to the selective flotation of the minerals from their ores and have established that mineral flotation is an interfacial phenomenon brought about fundamentally by the selective adsorption of a surfactant onto a mineral surface. Factors which have been found to influence adsorption include surfactant concentration, $\mathrm{pH}$, temperature and the presence of inorganic ions in the ore pulp, the degree of adsorption is intimately related to flotation. Flotation technique is often employed in the separation of solids of similar densities which cannot be separated by gravity using jigging and tabling [6-9].

Soap molecules exhibit amphipatic characteristics and as such are able to alter the surface properties of a system by their preferential orientation for optimum interaction at the interface [8]. A crude castor oil is a pale straw colour but turns colourless or slightly yellowish after refining and bleaching. The unrefined oil has specific odor, purification process. Like any other edible vegetable oils and animal fats, it is a triglyceride, which chemically is a glycerol molecule with each of its three hydroxyl group esterified with a long clown fatty acid. Majorly the unsaturated hydroxylated 12-hydroxy, 9octadecenoic acid, known as ricinoleic acid. The fatty acid composition of a typical castor oil contains about $87 \%$ of ricinoleic acid [10].

Hematite (a solid oxide particle) when immersed in water develop surface electrical charge by adsorption or desorption of potential determining ions. In ferric oxide, these ions are $\mathrm{H}^{+}$and $\mathrm{OH}^{-}$, and ferric hyroxo-complex ions derived from the solid phase by dissolution, when any ions which are specifically adsorbed at the oxide surface are absent. It has been widely used as an adsorbent to remove heavy metal ions from water [11-16], because of two main reasons: its available in large quantity and a relatively low cost. Despite its high applicability as an adsorbent, there is still little or dearth of information on the adsorption of metallic soaps prepared from locally available oils onto hematite in aqueous media. This research is therefore aimed at investigating the efficiency of the adsorption of metallic soaps onto $\mathrm{Fe}_{2} \mathrm{O}_{3}$ in aqueous media with generated data that explain adsorption phenomenon via applicability of suitable adsorption isotherm models and to investigate the role played by electrostatic interaction in the adsorption of the metallic soaps through the influence of ionic charge and ionic concentration on the adsorbate-adsorbent interaction in aqueous solution which will culminate in the ultimate prediction for the optimal design of an appropriate mineral flotation processing plants with these soaps as collectors' reagents.

\section{MATERIALS AND MeTHOdS}

\subsection{Sampling}

The adsorbent, metallic ores (hematite; $\alpha-\mathrm{Fe}_{2} \mathrm{O}_{3}$ ) procured from Itakpe, Kogi state, Nigeria $(76.9 \%)$ were crushed in laboratory using crushers. Gravimetric method jigging and tabling was employed in removing silineous materials, while magnetic separation method was used in separating magnetic materials from the ore samples. Sieve analyses were performed using standard sieve plates to obtain sample of hematite in required sizes. Solutions of reagents were prepared with distilled water, $\mathrm{NaOH}$ and $\mathrm{HCl}$ solutions were used for $\mathrm{pH}$ adjustments. Chemical reagents analar grade (of not less than 98\% purity) were used in this study. Determination of specific area (SSA) was done [17].

\subsection{Soap Preparation}

Derived adsorbates viz; $\mathrm{AI}^{3+}, \mathrm{Ca}^{2+}$ and $\mathrm{K}^{+}$-soaps of ricinus oil were prepared by carefully following the method described elsewhere [18] with slight modification. In this method, $50 \mathrm{~g}$ of ricinus oil was added to each $50 \mathrm{ml}$ of $30 \% \mathrm{KOH}, \mathrm{Ca}(\mathrm{OH}) 2$ and Aluminum hydroxide. $30 \mathrm{ml}$ of ethanol was added into each of the $60 \mathrm{ml}$ beakers, heated at $90^{\circ} \mathrm{C}$ for 1 hour in a water bath with vigorous stirring until 
creamy pasty soaps are formed soaps are formed. $50 \mathrm{ml}$ hot saturated $\mathrm{NaCl}$ solution was then added to each of the pasty soaps with vigorous stirring for 15 minutes and allowed to cool overnight. The soap cakes formed on the surface of the lye were removed, dried and stored in plastic containers.

\subsection{Batch Adsorption Test}

In the reactor tank, the adsorbate/adsorbent interactions were labeled as $\mathrm{AI}^{3+}$ soap/hematite, $\mathrm{Ca}^{2+}$ soap/hematite and $\mathrm{K}^{+}$soap/hematite. These formulations were obtained from a collecting $0.2 \mathrm{~g}$ of hematite into a reactor tank $\left(100 \mathrm{~cm}^{3}\right.$ Erlenmeyer flask). $25 \mathrm{~cm}^{3}$ of each aqueous soap solutions was added. The reaction was enhanced using a mechanical shaker at 120 oscillations per minute followed by centrifuge at $150 \mathrm{rpm}$. Upon filtration of the decanted samples, the filtrate was measured for equilibrium phase concentration (Ce) using the pre designed calibration curve.

The amount of adsorbates adsorbed onto a unit mass of the adsorbent qe in $\mathrm{mg} / \mathrm{g}$ is computed as [19]

$q_{e}=\left(C_{o}-C_{t}\right) \frac{v}{w}$

Where $\mathrm{Co}$ and $\mathrm{Ce}$ are the aqueous phase and equilibrium phase dye concentration in $\mathrm{mg} / \mathrm{L}$ respectively. $\mathrm{V}$ is the volume of soap solution $\left(\mathrm{dm}^{3}\right)$ while $\mathrm{W}$ is the adsorbent (Hematite) mass.

\subsection{Adsorption Capacity as a Function of Ionic Charge}

To determine the effect of the ionic charge, $25 \mathrm{ml}$ of the different soap solutions of the same concentration $\left(2.0 \times 10^{-2} \mathrm{mmol} / \mathrm{L}\right)$ was mixed with an equal volume of $2.0 \times 10^{-2} \mathrm{mmol} / \mathrm{L}$ potassium nitrate solution. nitrate solution, the mixture was stirred thoroughly and its conductance measured as $\mathrm{K}_{1} .0 .25 \mathrm{~g}$ of the metal ore was added individually to the mixture, shaken for one hour, centrifuged and filtered. The conductance of the clear filtrate was also measured and reported as $\mathrm{K}_{2}$. The procedure was repeated using different concentrations of potassium, barium and aluminum nitrates to determine the effect of cations of increasing charge. The procedure was also repeated using sodium nitrate, sodium sulphate and sodium phosphate at various concentrations to observe the effect of anions of increasing charges on the different soaps adsorbed onto the metal ore. The conductance difference $(\mathrm{K} 1-\mathrm{K} 2)$ is the equilibrium conductance due to adsorption of adsorbate onto adsorbents and the equilibrium soap concentration was obtained from the calibration graph. The adsorption capacity (qe) was determined using Eq.1.

\section{RESULTS AND DISCUSSION}

\subsection{Results}

Table1. Langmuir experimental data for $\mathrm{K}^{+}$and $\mathrm{Ca}^{2+}$ soaps of Ricinus oil onto a metal ore

\begin{tabular}{|l|l|l|l|l|l|}
\hline Metallic soap & Langmuir equation & Linear $\mathrm{R}^{2}$ & \multicolumn{4}{|l|}{ Constants } & $\mathrm{Ka}$ \\
\cline { 3 - 6 } & & & qm & $\mathrm{Ka}$ & $\mathrm{RL}$ \\
\hline $\mathrm{K}^{+}$ & $0.388 \mathrm{x}-3.140$ & 0.635 & 0.218 & 0.0810 & 8.105 \\
\hline $\mathrm{Ca}^{2+}$ & $0.542 \mathrm{x}-3.575$ & 0.803 & 0.280 & 0.978 & 6.589 \\
\hline
\end{tabular}

Table2. Freundlich experimental data for $\mathrm{K}^{+}$and $\mathrm{Ca}^{2}$ soaps of Ricinus oil onto a metal ore

\begin{tabular}{|l|l|l|l|l|}
\hline Metallic soap & Freundlich equation & Linear $\mathrm{R}^{2}$ & \multicolumn{2}{|l|}{ Constants } \\
\cline { 3 - 5 } & & & $\mathrm{n}$ & $\mathrm{Kf}$ \\
\hline $\mathrm{K}^{+}$ & $1.702 \mathrm{x}+1.666$ & 0.808 & 0.588 & 46.345 \\
\hline $\mathrm{Ca}^{2+}$ & $2.138 \mathrm{x}+1.973$ & 0.695 & 0.468 & 93.972 \\
\hline
\end{tabular}

Table3. Temkin experimental data for $\mathrm{K}^{+}$and $\mathrm{Ca}^{2}$ soaps of Ricinus oil onto a metal ore

\begin{tabular}{|l|l|l|l|l|}
\hline Metallic soap & Temkin Linear equation & $\mathrm{R}^{2}$ & \multicolumn{2}{|l|}{ Constants } \\
\cline { 3 - 5 } & & & $\mathrm{b}$ & $\mathrm{A}$ \\
\hline $\mathrm{K}^{+}$ & $30.36 \mathrm{x}-2.970$ & 0.816 & 81.580 & 0.9086 \\
\hline $\mathrm{Ca}^{2+}$ & $40.85 \mathrm{x}-4.197$ & 0.793 & 61.104 & 0.9017 \\
\hline
\end{tabular}

Table4. BET experimental data for $\mathrm{K}^{+}$and $\mathrm{Ca}^{2}$ soaps of Ricinus oil onto a metal ore

\begin{tabular}{|l|l|l|l|l|}
\hline Metallic soap & BET Linear equation & \multirow{2}{*}{$\mathrm{R}^{2}$} & Constants \\
\cline { 3 - 5 } & & & $\mathrm{C}_{\mathrm{BET}}$ & $\mathrm{qs}$ \\
\hline $\mathrm{K}^{+}$ & $0.011 \mathrm{x}+0.378$ & 0.727 & 1.029 & 2.570 \\
\hline $\mathrm{Ca}^{2+}$ & $0.014 \mathrm{x}+0.249$ & 0.752 & 1.056 & 3.803 \\
\hline
\end{tabular}


Metallic Soaps of Ricinoleic Acid: Adsorption Isotherms and Effects of Ionic Charge

Table5. Dubinin Radushkevich experimental data for $\mathrm{K}^{+}$and $\mathrm{Ca}^{2}$ soaps of Ricinus oil onto a metal ore

\begin{tabular}{|l|l|l|l|l|}
\hline Metallic soap & Dubinin Linear equation & Radushkevich $\mathrm{R}^{2}$ & \multicolumn{3}{|l|}{ Constants } \\
\cline { 3 - 5 } & & & $\mathrm{B}_{\mathrm{D}}$ & $\mathrm{E}$ \\
\hline $\mathrm{K}^{+}$ & $-3 \mathrm{E}+07-6 \mathrm{E}+07$ & 0.679 & $1.5 \mathrm{E} 74$ & $1.826^{*} 10^{-}$ \\
\hline $\mathrm{Ca}^{2+}$ & $-4 \mathrm{E}+07 \mathrm{x}-8 \mathrm{E}+07$ & 0.811 & $2.0 \mathrm{E} 74$ & $1.581^{*} 10^{-}$ \\
\hline
\end{tabular}

Table6. Adsorption experimental data for Potassium Ricinus oil soap uptake onto a metallic ore

\begin{tabular}{|r|r|r|r|r|r|r|}
\hline Ionic conc & $\mathrm{qe}\left(\mathrm{k}^{2+}\right)$ & $\mathrm{qe}\left(\mathrm{Ba}^{2+}\right)$ & $\mathrm{qe}\left(\mathrm{Al}^{3+}\right)$ & $\mathrm{qe}\left(\mathrm{NO}_{3}{ }^{-}\right)$ & $\mathrm{qe}\left(\mathrm{SO}_{4}{ }^{2-}\right)$ & $\mathrm{qe}\left(\mathrm{PO}_{4}{ }^{3-}\right)$ \\
\hline 0.202 & 0.0784 & 0.0792 & 0.0804 & 0.0778 & 0.0793 & 0.0797 \\
\hline 0.506 & 0.0785 & 0.0798 & 0.0819 & 0.0794 & 0.0797 & 0.0792 \\
\hline 1.011 & 0.0766 & 0.0796 & 0.083 & 0.0797 & 0.0799 & 0.0789 \\
\hline 1.518 & 0.078 & 0.0801 & 0.0812 & 0.0793 & 0.0797 & 0.0783 \\
\hline 2.023 & 0.078 & 0.0801 & 0.0812 & 0.0793 & 0.0789 & 0.0791 \\
\hline 3.035 & 0.078 & 0.0801 & 0.0812 & 0.0793 & 0.0789 & 0.0791 \\
\hline
\end{tabular}

Table7. Adsorption experimental data for Calcium Ricinus oil soap uptake onto a metallic ore

\begin{tabular}{|r|r|r|r|r|r|r|}
\hline Ionic conc & $\mathrm{qe}\left(\mathrm{k}^{2+}\right)$ & $\mathrm{qe}\left(\mathrm{Ba}^{2+}\right)$ & $\mathrm{qe}\left(\mathrm{Al}^{3+}\right)$ & $\mathrm{qe}\left(\mathrm{NO}_{3}{ }^{-}\right)$ & $\mathrm{qe}\left(\mathrm{SO}_{4}{ }^{2-}\right)$ & $\mathrm{qe}\left(\mathrm{PO}_{4}{ }^{3-}\right)$ \\
\hline 0.202 & 0.0845 & 0.0838 & 0.085 & 0.0833 & 0.0825 & 0.0808 \\
\hline 0.506 & 0.0824 & 0.0844 & 0.0866 & 0.0833 & 0.0814 & 0.0804 \\
\hline 1.011 & 0.0827 & 0.0856 & 0.0874 & 0.0825 & 0.0817 & 0.08 \\
\hline 1.518 & 0.0833 & 0.0872 & 0.0884 & 0.0821 & 0.0812 & 0.0791 \\
\hline 2.023 & 0.0833 & 0.0872 & 0.0884 & 0.0821 & 0.08 & 0.0783 \\
\hline 3.035 & 0.0833 & 0.0872 & 0.0884 & 0.0821 & 0.08 & 0.0783 \\
\hline
\end{tabular}

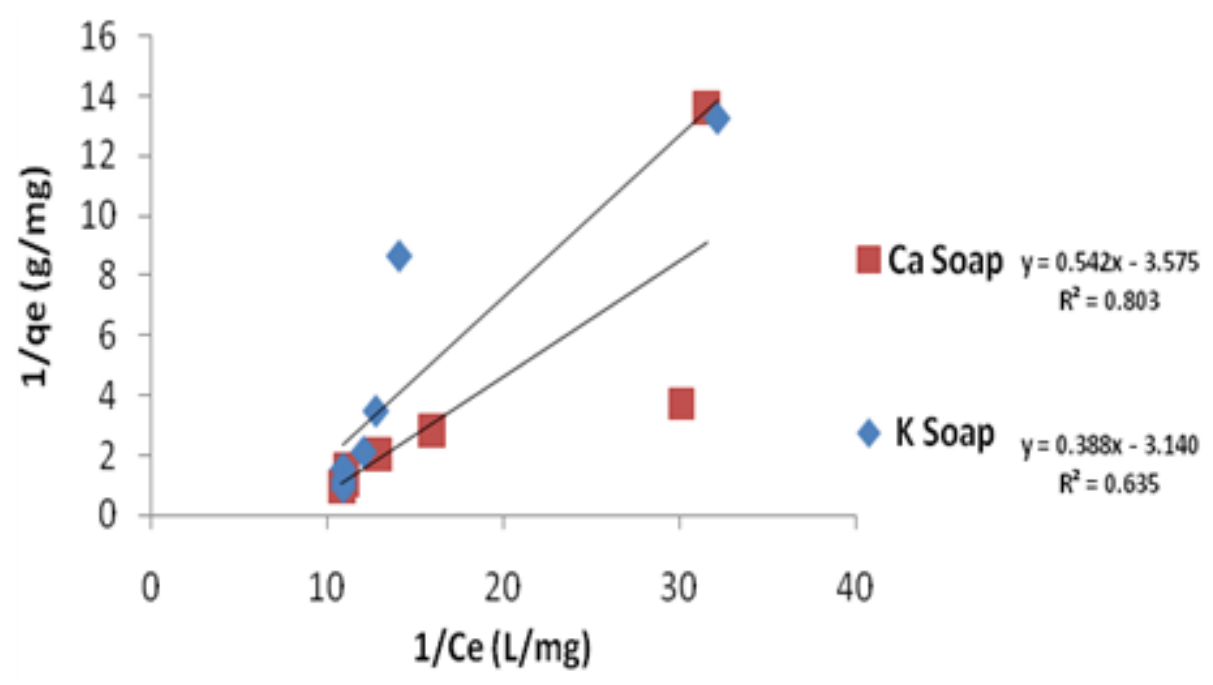

Fig1. Langmuir isotherm for $\mathrm{K}^{+}$and $\mathrm{Ca}^{2+}$ soaps of Ricinus oil uptake onto Heamatite

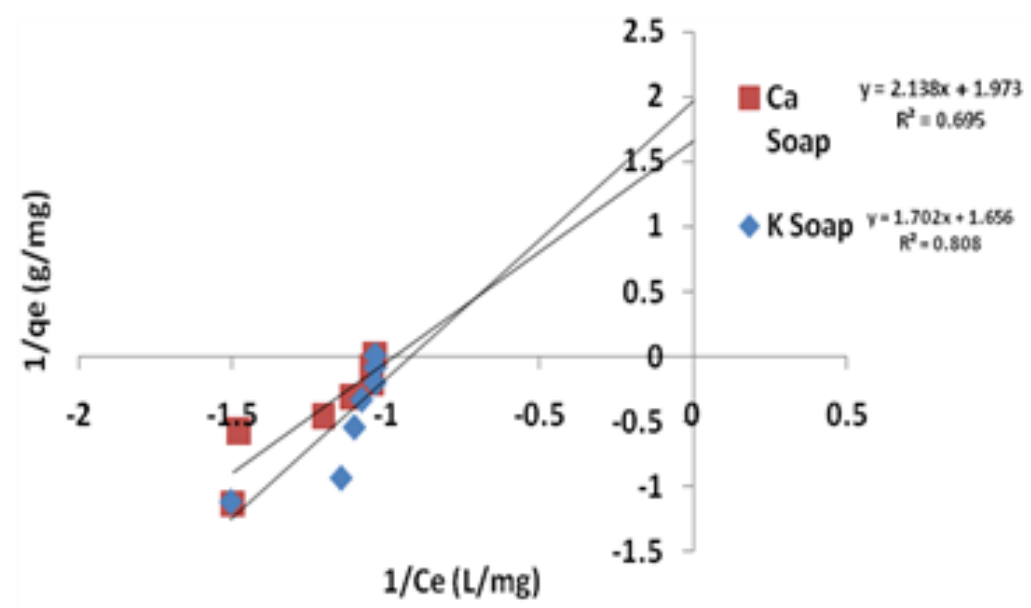

Fig2. Freundlich Isotherm for $\mathrm{K}^{+}$and $\mathrm{Ca}^{2+}$ soaps of Ricinus oil uptake onto Heamatite 


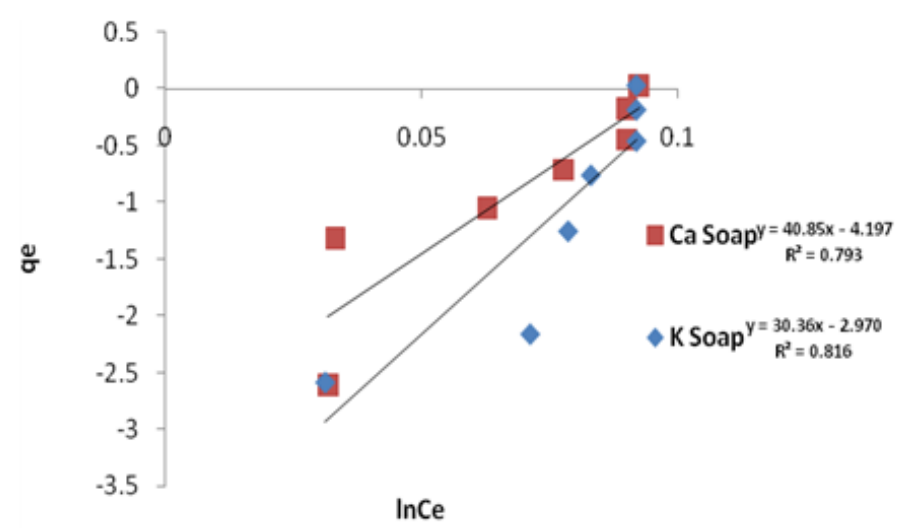

Fig3. Temkin Isotherm for $\mathrm{K}^{+}$and $\mathrm{Ca}^{2+}$ soaps of Ricinus oil uptake onto Heamatite

$$
\text { Da Soap } \begin{gathered}
\mathrm{y}=0.014 \mathrm{x}+0.249 \\
\mathrm{R}^{2}=0.752
\end{gathered}
$$

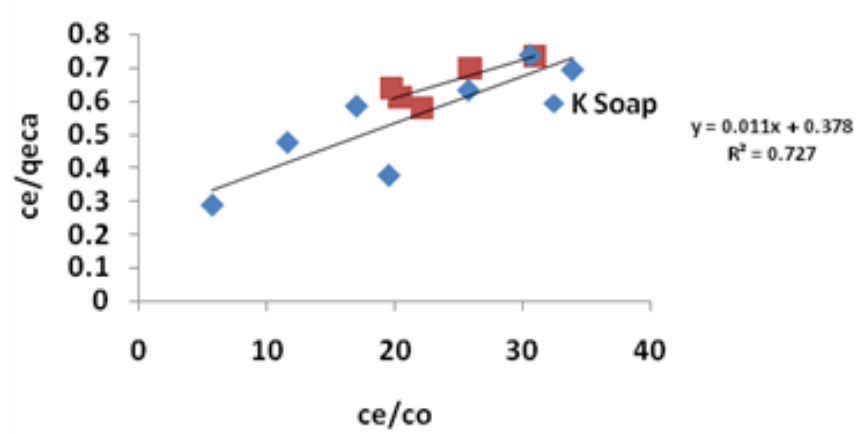

Fig4. BET Isotherm for $\mathrm{K}^{+}$and $\mathrm{Ca}^{2+}$ soaps of Ricinus oil uptake onto Heamatite

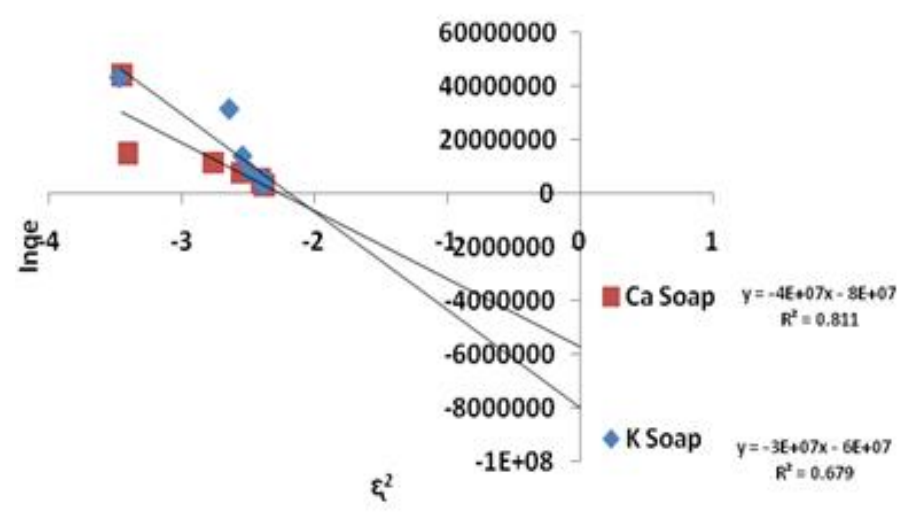

Fig5. Dubinin Radushkevich Isotherm for $\mathrm{K}^{+}$and $\mathrm{Ca}^{2+}$ soaps of Ricinus oil uptake onto Heamatite

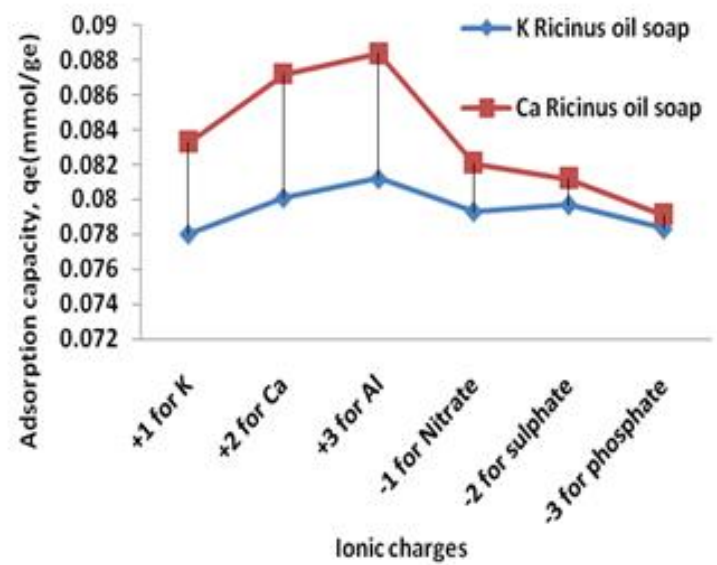

Fig6. Plot of adsorption capacity at equilibration concentration (1.158 $\mathrm{mmol} / \mathrm{L})$ for different ionic charges 


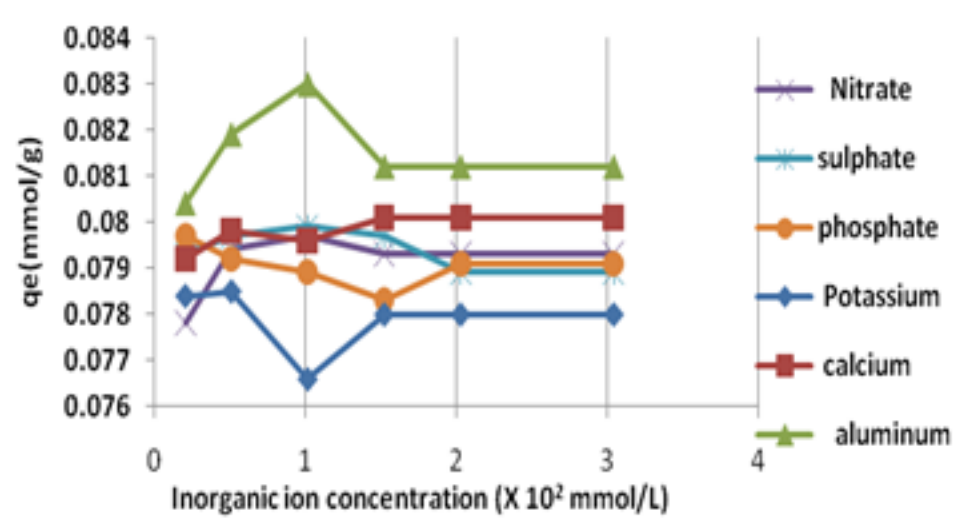

Fig7. Effect of ionic concentrations on the adsorption of Potassium Ricinus (Castor seed) soap onto a metallic ore

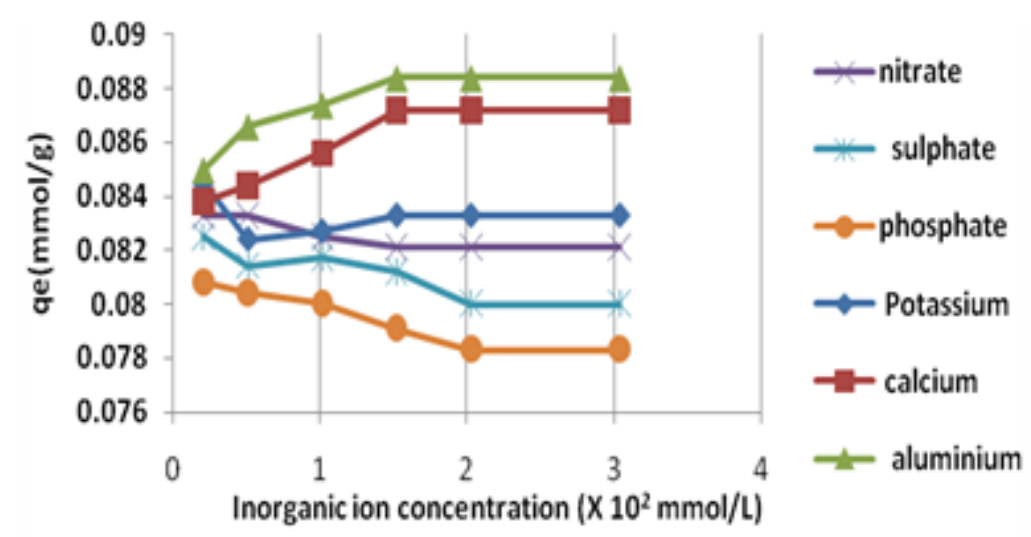

Fig8. Effect of ionic concentrations on the adsorption of calcium Ricinus (Castor seed) soap onto a metallic ore

\section{DISCUSSION}

Isotherm usually explains the relationship between the concentration of adsorbate at solid phase in relation to its concentration at equilibrium phase. In this research, five isotherms were used to model equilibrium data obtained for metallic soaps of castor seed oil (Ricinus) onto derived $\mathrm{Fe}_{2} \mathrm{O}_{3}$ adsorbent. The isotherm constants (Tables 1-5) were derived from the equilibrium data (tables 5 and 6) which are typical of the plots (figures 1-5). Three of these isotherms (viz: Langmuir, Freundlich and BET) explain surface coverage or layer coverage while the other two isotherms (Temkin and Dubinin Radushkevich) explain certain energy parameter as it influences adsorption.

A positive correlation coefficient values range of 0.635 to 0.816 is indication that the entire isotherms are useful in modeling adsorption phenomenon in this research.

Table 1 was based on the Langmuir isotherm. The $\mathrm{R}^{2}$ values representing coefficient of determination or applicability supports the fact that the adsorption of divalent $\left(\mathrm{Ca}^{2+}\right)$ metallic soap is best explained using Langmuir equation $\left(\mathrm{R}^{2}=0.803\right)$ and that the adsorption of $\mathrm{Ca}^{2+}$ Ricinus soap onto the adsorbent (hematite) is onto a surface of uniform site energy this is also applicable to the $\mathrm{K}^{+}$soap of the same oil. $\mathrm{R}_{\mathrm{L}}$ values which are the essential of the Langmuir equation are below 1 being an indication of favourable adsorption.

Figure 2 is a reverse situation in favour of adoption of Friendlich model $\left(\mathrm{R}^{2}=0.808\right)$ to interpret $\mathrm{K}^{+}$ soap uptake onto hematite. Unlike the $\mathrm{Ca}^{2+}$ soap (with lower $\mathrm{R}^{2}$ of 0.695 ) the $\mathrm{K}^{+}$soap can be best explained as one where surface coverage is heterogeneous and sorption is onto adsorbent of unequal site energies. The Freundlich constant $\mathrm{K}_{\mathrm{f}}$ (which relates to adsorption capacity) are within the range 46.345 and 93.972. Adsorption experimental run with highest adsorption capacity $\mathrm{K}_{\mathrm{f}}$, has the least $\mathrm{n}$ value (0.468) which depicts more heterogeneity since $\mathrm{n}$ values between 0 and 1 is a measure of heterogeneity.

Table 4 clearly showed that there is no considerable difference as to the extent for which both $\mathrm{K}^{+}$and $\mathrm{Ca}^{2+}$ soaps uptake are modeled using BET isotherm model. $\mathrm{Ca}^{2+}$ soap uptake as interpreted by the 
BET model gave high saturation capacity (qs $=3.803 \mathrm{mmol} / \mathrm{g}$ ) and high energy of surface interaction value $\left(\mathrm{C}_{\mathrm{BET}}\right.$ of $\left.1.056 \mathrm{~L} / \mathrm{mmol}\right)$ compared to the low value by the corresponding $\mathrm{K}^{+}$- Ricinus soap uptake.

Table 5 represents the Dubinin Radushkevich experimental constants for metallic soap uptake. Typical adsorption is termed favourable at lower energy demand. The mean free Energy, as derived from the sorption energy in a relation described earlier as $E=\left[1 / \sqrt{ } 2 B_{D}\right]$.

Sorption of both soaps presented $\mathrm{E}$ value ranges as $1.581 \times 10^{-4}$ and $1.826 \times 10^{-4} \mathrm{KJ} / \mathrm{mmol}$. The applicabiltity of the model favours $\mathrm{Ca}^{2+}$ ricinus soap uptake (with value of $\mathrm{R}^{2}=0.811$ ) than the $\mathrm{K}^{+}$ ricinus soap $\left(R^{2}=0.679\right)$.

The figures 1 to 5 are typical of those from which constants on Tables 1 to 5 were generated. Representations of these figures were comparable to those published in literatures. They all presented positive coefficient of determination $\left(\mathrm{R}^{2}\right)$ values, which are indication that their constant can be used to explain adsorption phenomenon.

\subsection{Effect of Ionic Charge on Adsorption Capacity (qe)}

Tables 6 and 7 represent experimental data of adsorption capacity (qe) values estimated for both monovalent $\left(\mathrm{K}^{+}\right)$and divalent $\left(\mathrm{Ca}^{2+}\right)$ - Ricinus oil soap onto metallic ore (hematite). It is evidenced that at certain ionic concentration $(1.518 \mathrm{mmol} / \mathrm{L}$ as shown in column 1 of tables 6 and 7), equilibration is attained after which the rate of adsorption equals that of desorption until constant values are attained, qe at this concentration are presented as figure 6.

Figure 6 shows that the adsorption capacity value at the set point or concentration of equilibration is charge dependent. Qe values increased linearly for cationic $\left(\mathrm{K}^{+}, \mathrm{Ba}^{2+}\right.$ and $\left.\mathrm{Al}^{3+}\right)$ spiked Ricinus soaps adsorption. The reverse case was observed for the anionic $\left(\mathrm{NO}_{3}{ }^{-}, \mathrm{SO}_{4}{ }^{2-}\right.$ and $\left.\mathrm{PO}_{4}{ }^{3-}\right)$ spiked soaps of Ricinus oil where qe at equilibration decreases with increase in ionic charge.

Figures 7 and 8 investigate the effect of ionic charges or qe, not only for the set or initial concentration at equilibration for the entire experimental runs. It was observed that for cationic spiked soaps, adsorption capacity increased with increase concentration until a maximum is attained after which concentration became constant. The reverse is the case for anionic spiked soaps of both $\mathrm{K}^{+}$and $\mathrm{Ca}^{2+}$ soaps of Ricinus oil.

\section{CONCLUSION}

This work presents results of studies carried out to investigate the adsorption performance via the use of different isotherm models as well as to investigate the role played by ionic charges. The experimental runs were performed at a temperature of $27 \pm 02^{\circ \mathrm{cc}}$, in batch reactors. Experimental results showed that it is the most applicable isotherm model does not necessarily depend on adsorbates adsorbent interaction but adsorption itself does depend on the nature of adsorbates, ionic charge and concentration. All the adopted isotherms presented positive determination coefficients to justify their usage in interpreting the adsorption phenomenon. From a generalized point of view, the adsorbent compares well with those in literatures while the nature of soap, role played by ionic charge and concentration are critical in adsorption studies.

\section{Nomenclatures / Abbreviation}

$\mathrm{Ce}$ - adsorbates concentration at equilibrium time ( $\mathrm{mol} / \mathrm{L})$.

$\mathrm{Co}-$ initial adsorbate concentration in solution $(\mathrm{mol} / \mathrm{L})$

qe - amount of adsorbate in the adsorbent at equilibrium $(\mathrm{mg} / \mathrm{g}$ )

qe.cal -calculated amount of adsorbate at equilibrium

qe.exp - measured or experimental amount of adsorbate at equilibrium.

$\mathrm{R} 2$ - coefficient of determination

$\alpha$ (gmg-1min-2)- initial rate constant

$\beta$ (mgg-1min-1) - desorption constant

- Non-linear chi square test. 
Kf Freundlich constant (which relates to adsorption capacity)

RL values which are the essential of the Langmuir

BD sorption energy

E Mean free energy

\section{Isotherm Equations}

$\log \mathrm{q}_{e}=\log \mathrm{k}_{f}+\frac{1}{n} \log \mathrm{c}_{e}$

Freundlich equation

$\frac{1}{q_{e}}=\frac{1}{k_{a} q_{m} c_{e}}+\frac{1}{q_{m}}$

Langmuir model

$$
R_{L}=\frac{1}{1+k_{a} c_{o}}
$$

A dimensionless constant separation factor

$$
\frac{c_{e}}{q_{e}\left(c_{s}-c_{e}\right)}=\frac{B-1}{B \mathrm{Q}^{\mathrm{o}}} \frac{c_{e}}{c_{s}}+\frac{1}{B \mathrm{Q}^{\mathrm{o}}}
$$

Linear form, Brunauer-Emmet-Teller (BET)

$$
\ln q_{e}=\ln q_{s}-B \boldsymbol{\varepsilon}^{2}
$$

Dubinin Radushkevich equation

$$
\varepsilon=R T \ln \left[1+\frac{1}{c_{e}}\right]
$$

Component of Dubinin Radushkevich equation

$q_{e}=B \ln A+B \ln c_{e}$

Temkin Equation

$$
B=\frac{R T}{b}
$$

Component of Temkin Equation

\section{REFERENCES}

[1] Ozer, D., Dursun, A., Ozer, A. (2007) Hazard mat. 146,262-269.

[2] Yuh, H. (2006). Pol. J. Environ Stud. 15(1), 81-86.

[3] Chongrak K; Eric H; Noureddine A; and Jean P. (1998). Cotton Sci. 2,164-173.

[4] Itodo AU, Abdulrahman, FW, Hassan LG, Maigandi SA, Happiness UO (2010) Knowledge Review: 20 (1), 126-131

[5] Itodo AU, Abdulrahman FW, Hassan LG, Maigandi SA, Happiness UO. (2009), International journal of chemical sciences, 2(1), 27-33.

[6] Asuquo, J. E, Anusiem, A. C. I and Etim, E. E. (2012) International Journal of Modern Chemistry. 2(2): 74-83.

[7] Ibezim-Ezeani, M. U.; Anusiem, A. C. I. (2010) E-journal of chemistry, 2010, 7(4), 1491-1497.

[8] Ibezim-Ezeani, M. U.; Anusiem, A. C. I. (2009) Sci. Afric., 8, 31-41.

[9] Vinod, V. P and Anirudhan, T. S. (2001) Journal of chemical technology and biotechnology, 77, 92-101. 
[10] Akpan, U.G.; Jimoh, A.; Mohammed, A. D. (2006) Leonardo J. Sci. 8, 43-52.

[11] S. Y. Zeng, K. B. Tang, T. W. Li, Z. H. Liang, D. Wang, Y. K. Wang and W. W. Zhou (2011), the Journal of Physical Chemistry 111, 10217-10225.

[12] B.H. Jeon, B. A. Dempsey, W. D. Burgos, R. A. Royer and E. E. Roden, (2004) Water Research, 38(10), 2499-2508.

[13] Y. Mamindy-Pajany, C. Hurel, N. Marmier and M. Roméo (2009). Comptes Rendus Chimie, 12 (8), 876881.

[14] M. Mohapatra, K. Rout, B. K. Mohapatra and S. Anand, (2009) Journal of Hazardous Materials.. 166, (2-3-),1506-1513.

[15] W.-S. Choi, H.-M. Yang, H.-Y. Koo, H.-J. Lee, Y.-B. Lee, T.-S. Bae and I.-C. Jeon, S. (2010) Ad-vanced Functional Materials, 20 (5), 820-825.

[16] Y. H. Chen and F. A. Li, (2010) Journal of Colloid and Interface Science, 347(2), 277-281.

[17] A. B. Cerato and A. J. Lutenegger. (2002) Geotech. Test 25(3),1-7.

[18] P. Tooley.( 1976,) Experiments in applied chemistry. Jon Murray London, p. 29.

[19] A. U. Itodo, A. Usman, A. Grace, H. U.Itodo and V. C. Ugboaja (2012) Journal of Enviro-nment Protection. 3(3), 288-295.

Citation: E. Etim, "Metallic Soaps of Ricinoleic Acid: Adsorption Isotherms and Effects of Ionic Charge", International Journal of Advanced Research in Chemical Science (IJARCS), vol. 4, no. 6, pp. 31-39, 2017. http://dx.doi.org/10.20431/2349-0403.0406004

Copyright: (C) 2017 Authors. This is an open-access article distributed under the terms of the Creative Commons Attribution License, which permits unrestricted use, distribution, and reproduction in any medium, provided the original author and source are credited. 